\section{$16^{\circ}$ \\ ERGODESIGN \\ USIHC \\ CINAHPA}

$16^{\circ}$ Ergodesign - Congresso Internacional de Ergonomia e Usabilidade de Interfaces Humano Tecnológica: Produto, Informações Ambientes Construídos e Transporte

$16^{\circ}$ USIHC - Congresso Internacional de Ergonomia e Usabilidade de Interfaces Humano Computador

CINAHPA | 2017 - Congresso Internacional de Ambientes Hipermídia para Aprendizagem.

\title{
JOGOS DIGITAIS E EMPATIA - ATRAVESSANDO UM MUNDO DE DESAFIOS EM CADEIRA DE RODAS VIRTUAL.
}

\section{GAMES AND EMPATHY - THROUGH A WOLRD OF CHALLANGES IIN A VIRTUAL WHEELCHAIR.}

\author{
Fabiano Rodrigues de Paula ${ }^{1}$, Tecg $^{\mathbf{}}$ \\ Renata da Silva Machado ${ }^{2}$, Espec
}

(1) Ceet Vasco Coutinho

e-mail:fabiano.rpaula@gmail.com

(2) Ceet Vasco Coutinho

e-mail: reusmachado@gmail.com

Palavras Chaves: Realidade virtual, assistividade, jogos

Esse relato de experiência consiste em apresentar o desenvolvimento e apresentação de um jogo digital, que busca demonstrar para as pessoas que não utilizam cadeiras de rodas os mesmos desafios encontrados por pessoas que as utilizam. Trabalho desenvolvido utilizando uma cadeira de rodas conectado a um arduino, óculos de realidade virtual, comera de captura de movimento e computador. A metodologia adotada foi um estudo de caso com embasamento em pesquisa bibliográfica e análise de dados quantitativos. Os resultados alcançados apontam para uma mudança de percepção dos jogadores sobre a dificuldade que as pessoas que utilizam cadeira de rodas enfrentam. Concluímos ressaltando o potencial que os jogos digitais possuem, para produzir empatia e gerar debate social sobre temas sensiveis ou ignorados.

\section{Key-words : Virtual Reality, assistivity, games}

This report of experience consists in presenting the development and the presentation of a game, which seeks to demonstrate to people who do not use wheelchairs the same challenges encountered by people who use them. Developed using a wheelchair connected to an arduino, virtual reality glasses, motion capture camera and computer. The methodology adopted was a case study based on bibliographic research and analysis of quantitative data. The results show a change in perception, in players, about the difficulty that people who use wheelchairs face. We conclude highlighting the value of game to produce empathy and generate social debate on sensitive or ignored topics. 


\section{$16^{\circ}$ \\ ERGODESIGN USIHC CINAHPA}

\section{Introdução}

Este texto vai tratar da experiência de desenvolvimento de um jogo digital de realidade virtual, que busca tornar visível os problemas das pessoas em cadeira de rodas, por meio da explicitação das barreiras que enfrentam. Partimos do pressuposto que ao confrontar uma pessoa sem deficiência com as mesmas barreiras e dificuldades vividas por uma pessoa em cadeira de rodas utilizando um jogo, poderíamos sensibilizar o jogador, e desse modo causar uma alteração de percepção sobre as pessoas em cadeiras de rodas, que são ignoradas em nossa sociedade, se tornando invisíveis para grande parte da população. $\mathrm{Na}$ Figura 1 temos um exemplo do jogo sendo utilizado.

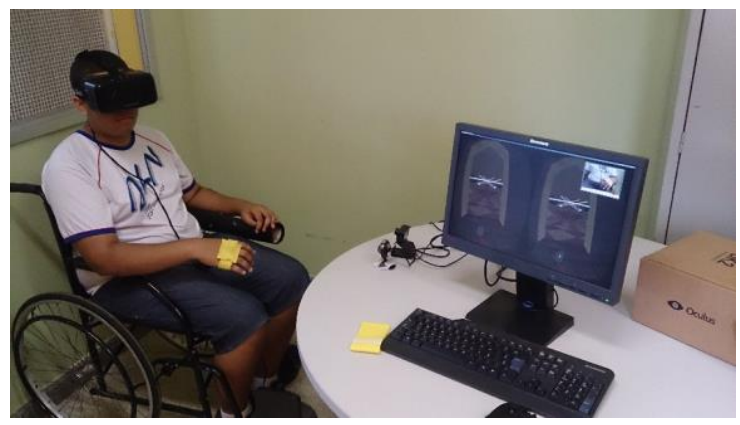

Figura 1 Jogo em funcionamento em uma escola de ensino médio. Aluno visualizando o jogo por meio de óculos de realidade virtual, movendo a cadeira com manete acoplada a cadeira de rodas e controlando mão por meio de captura de movimento.

\section{Fonte: Própria}

A Lei Brasileira de Inclusão da Pessoa com Deficiência [Brasil, 2015] entende a necessidade da inclusão e participação dos deficientes na sociedade, entretanto esse tema se torna delicado quando confrontado com a invisibilidade dessas pessoas dentro do campo social e educacional.

O pensamento discriminatório sempre foi latente neste cenário por ser de ordem mais fácil, ou seja, observar as dificuldades, os obstáculos e às vezes as aparências do deficiente, no lugar de seu potencial, foi uma postura que perpetuou durante anos a invisibilidade prática desse público. [ALECRIM, 2014, sem página]. $16^{\circ}$ Ergodesign - Congresso Internacional de Ergonomia e Usabilidade de Interfaces Humano Tecnológica: Produto, Informações Ambientes Construídos e Transporte

$16^{\circ}$ USIHC - Congresso Internacional de Ergonomia e Usabilidade de Interfaces Humano Computador

CINAHPA | 2017 - Congresso Internacional de Ambientes Hipermídia para Aprendizagem.

Entendemos nesse sentido, que o processo de inclusão do deficiente na sociedade deve incluir programas que deêm visibilidade ao deficiente e às dificuldades que ele enfrenta, apresentando ao público que não possui deficiência a dificuldade enfrentada por pessoas que encontram barreiras que obstruem sua efetiva participação na sociedade.

\section{Trabalhos Relacionados}

Sens e Pereira [2015] analisam o mercado de jogos em relação a acessibilidade realizando a análise de dois jogos assistivos. O texto dos autores reflete, dessa forma, as questões design que envolvem a produção de um jogo que busca sanar a dificuldade específica de um público, no caso os deficientes visuais. Conclui-se com a ressalva de que é uma utopia pensar em um jogo que atinja os públicos de maneira universal, entretanto aponta-se a visão de que o público com necessidades especiais já não é um fardo, e sim um nicho de mercado que pode ser buscado.

Ramalho et al [2014] ao produzir um jogo assistivo com Kinect para deficientes visuais, levanta questões sobre as interfaces acessíveis para deficientes visuais e maneiras de atender um público específico. Apontando que a tecnologia pode ser utilizada para melhorar a vida de pessoas com deficiência.

Cedro e Betini [2015] realizam uma importante contribuição teórica sobre o tema, ao apontar definições de acessibilidade e sua relação com jogos digitais, ainda destacam a importância das emoções no funcionamento de um jogo digital. Revelando que o jogo ocorre além de suas interações motoras.

Silva et al [2015] discustem a possibilidade da teoria da gamificação associada a teoria das emoções, revisando estudos que abordaram o tema. A importância dessa análise é constatar que o uso de jogos para provocar emoções já é uma abordagem usada dentro da academia. $\mathrm{O}$ estudo conclui que o game design pode ser usado para provocar emoção nos jogadores e afirma que essa emoção, se bem utilizada pode produzir um
Realização:
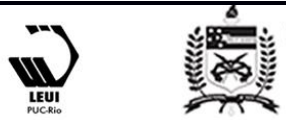


\section{$16^{\circ}$ \\ ERGODESIGN USIHC CINAHPA}

$16^{\circ}$ Ergodesign - Congresso Internacional de Ergonomia e Usabilidade de Interfaces Humano Tecnológica: Produto, Informações Ambientes Construídos e Transporte

$16^{\circ}$ USIHC - Congresso Internacional de Ergonomia e Usabilidade de Interfaces Humano Computador

CINAHPA | 2017 - Congresso Internacional de Ambientes Hipermídia para Aprendizagem. aprendizado eficiente.

\section{Metodologia}

Utilizamos a semana de ciência e tecnôlogia para colher dados quantitativos e qualitativos do público que utilizava o jogo de realidade virtual. A apresentação consistiu do uso do jogo em realidade virtual, apoiado por diversos dispositivos de imersão. Cada usuário teve a oportunidade de utilizar o jogo digital por um período aproximado de 3 minutos. No total 126 pessoas utilizaram o equipamento e em seguida responderam um questionário que buscava apontar a percepção dos mesmos sobre as dificuldades enfrentadas por pessoas que utilizam cadeiras de rodas. A pesquisa se focou em pessoas que não utilizavam cadeiras de rodas.

O objetivo do jogo digital é provocar a empatia do sujeito que não possui deficiência para com o portador de alguma deficiência, no caso do projeto: a deficiência motora das pernas. Um dos tipos de abordagem para alcançar o resultado esperado é a abordagem afectiva-emocional conforme descreve Gonçalves [2009]:

Uma abordagem afectiva-emocional, para a compreensão das experiências significativas (simulações) como base para o desenvolvimento da empatia e da aceitação social. A simulação (dramatização de determinados eventos) é o veículo principal para gerar a modificação de atitudes. A simulação é um conjunto de actividades, nas quais as tarefas devem ser negociadas sob condições simuladas de deficiência.[p.34]

Para provocar a simulação utilizamos um jogo digital apoiado por sistemas interação. Entendemos esses sistemas de interação como os dispositivos de entrada de dados do usuário/jogador para dentro do jogo digital.

Cabe explicar que o usário/jogador atua no jogo por meio do avatar " [....] que representa gráfica e diegesticaente o interator no mundo virtual e tridimensional do jogo," [GOMES, p.68], sendo assim, "[...] denota ter como sede a ideia de espaço virtual como lugar de inventar e reinventar a própria vida, o próprio corpo" [CRUZ; SILVA, 2010, p.101]. Como os autores salientam é possível por meio da realidade virtual, possuir um corpo saudável e sem deficiências.

Nesse sentido, entende-se que a homogeneização de condições de criação e perpetuação da corporeidade, presente nos ambientes virtuais, gera circunstâncias favoráveis para o rompimento de muitos paradigmas relativos ao corpo, pois, ao tornar a sua manifestação apenas um reflexo da vontade, dissipa-se, neste lugar, diversos (pre)conceitos apoiados em sua existência no mundo cotidiano. [CRUZ; SILVA, 2010, p.100]

\section{Projeto}

Quando desenvolvemos o jogo digital "Castelo do Alquimista" o objetivo foi subverter a ideia de corpo perfeito no mundo virtual e apresentar um corpo com limitações. Sendo que essas limitações, deveriam representar desafios de controle para o jogador. Logo, os controles do jogo são uma simulação dos controles de uma cadeira de roda motorizada. Nesse sentido, a maneira de controlar o jogo simula a de uma cadeira de rodas e o jogador é obrigado a atuar como uma pessoa com deficiência.

\subsection{Game Design}

O game é composto por uma série de quatro desafios que buscam representar de forma alegórica, as dificuldades encontradas por pessoas em cadeiras de rodas no cotidiano, essas dificuldades foram estilizadas como desafio de jogo. São eles:

Sala de Pedra - Encontrar um botão para abrir a porta.

Sala de Química - Pegar frascos e jogar dentro do caldeirão, abrindo caminho para a sala seguinte.

Sala da Biblioteca Andar 1 - Transformar uma escada em rampa.

Sala da Biblioteca Andar 2 - Erguer espelhos para ativar o final do jogo.
Realização:

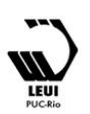




\section{$16^{\circ}$ \\ ERGODESIGN USIHC CINAHPA}

Os desafios do jogo foram pensados levando em considerações as dificuldades encontradas pelos usuário de cadeira de rodas nas atividades do dia a dia.

Nas duas primeiras ambientações: Sala De Pedra e Sala De Química, os botões e frascos que deveriam ser alcançados em cima de uma mesa, estes objetos não eram alcançados com facilidade se $o$ personagem posicionasse a cadeira de frente para $o$ objeto, mas eram mais facilmente alcançados, se a cadeira estivesse posicionada lateralmente, com um alcance maior dos braços.

A solução da Sala De Química envolve ainda, um pequeno monte de areia no chão, o jogador só consegue se deslocar entre as salas ao resolver um enigma para retirar a areia que está bloqueando o caminho da cadeira. A areia é um problema de deslocamento de usuários de cadeira de rodas no ambiente não virtual, por isso inserido no game como desafio. Na Sala Da Biblioteca, o jogador precisa levar o personagem para o segundo andar e a forma disponível ao jogador é uma escada. Dessa forma, o gamer precisa resolver um enigma para que no local da escada apareça uma rampa, que permita que este suba em sua cadeira de rodas para $\mathrm{o}$ andar seguinte.

Durante o período de elaboração do jogo foram realizadas diversos testes para verificar a jogabilidade mais adequada para transmitir a mensagem que o jogo continha, e foi percebido que pessoas não familiarizadas com jogos digitais gastavam mais tempo para resolver determinadas atividades de enigma, enquanto jogadores familiarizados as realizavam de maneira instantânea. Portanto, visando adaptaro game para um público não jogador, foi escolhido o desenvolvimento de "desafios de jogo" de baixo grau de dificuldade, como a dinâmica de toque em botões e pegar objetos. Foi criado um personagem em cadeira de rodas o qual é utilizado como avatar, Figura2, do jogador no mundo virtual. $16^{\circ}$ Ergodesign - Congresso Internacional de Ergonomia e Usabilidade de Interfaces Humano Tecnológica: Produto, Informações Ambientes Construídos e Transporte

$16^{\circ}$ USIHC - Congresso Internacional de Ergonomia e Usabilidade de Interfaces Humano Computador

CINAHPA | 2017 - Congresso Internacional de Ambientes Hipermídia para Aprendizagem.

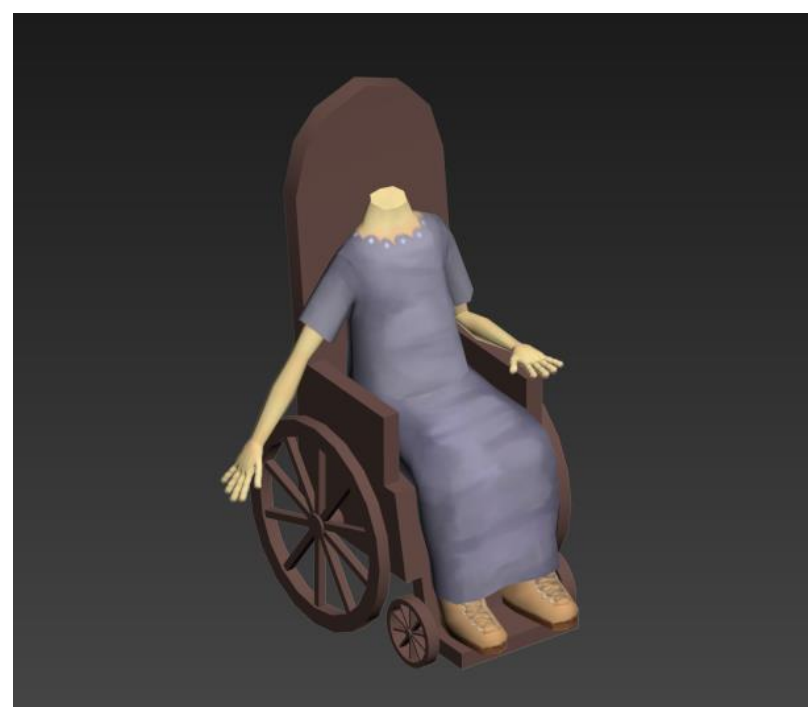

Figura 2 Modelo 3D do personagem jogador, corpo em uma cadeira de rodas.

Fonte: Própria

Os elementos de interação utilizados nesse jogo buscavam propiciar uma experiência imersiva ao jogador. Definindo imersão:

O termo foi introduzido recentemente na área das pesquisas para desenvolver projetos de realidade virtual e refere ao modo peculiar como o sujeito 'entra' ou 'mergulha' dentro das imagens e dos sons virtuais gerados pelo computador. [Machado apud Sato, 2009, p.45].

Santaella ainda destaca "no caso dos jogos computacionais, duas espécies de imersão estão operando simultaneamente: a absorção profunda, perceptica e psicológica, que é exigida por qualquer jogo de qualquer tipo e a imersão em um ciberambiente" [Santaella, 2009, p.61].

\subsection{Dispositivos}

Para garantir uma interação entre jogo e jogador. O design do jogo foi pensado de modo a que os elementos fossem semelhantes aos do cotidiano e propiciassem maior imersão. Portanto, embora o ambiente seja fantástico e fora da realidade do cotidiano, a forma de interagir com ele é semelhante àquela praticada no cotidiano. Os sistemas de entrada foram: 1 Cadeira de Rodas; 2 Manete; 3 Captura de Movimento; 4 Óculos de realidade virtual. 


\section{$16^{\circ}$ \\ ERGODESIGN USIHC CINAHPA}

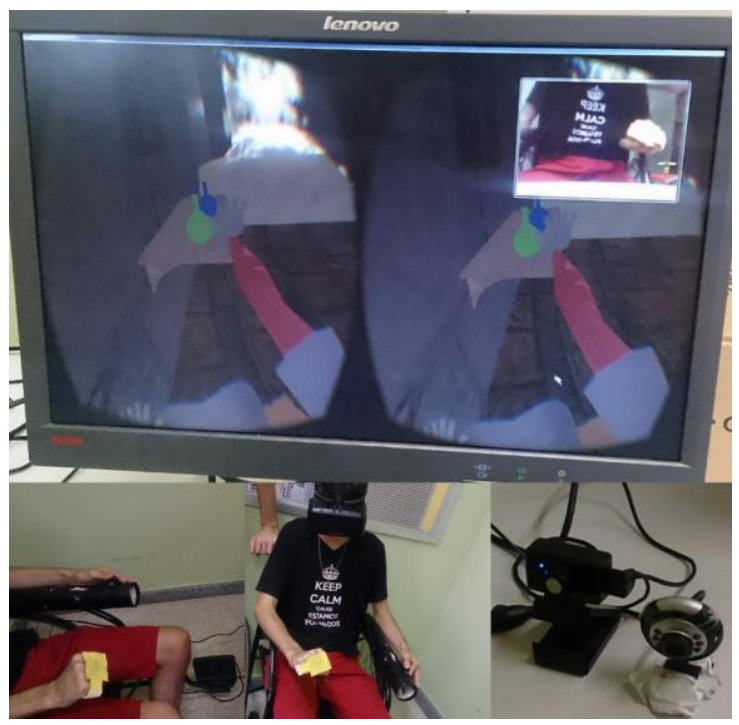

Figura 3 Representação dos Sistemas de Jogo: Monitor com o jogo virtual; Jogador controlando manete;

Jogador com oculos de realidade virtual; Câmera para capturar movimento da cabeça e câmera para capturar movimento da mão.

Fonte: Própria

\subsubsection{Cadeira de Rodas}

Foi adquirida uma cadeira de rodas, a qual foi utilizada como cadeira de jogo. O Usuário/Jogador que chegava ao evento se aproximava do objeto e a primeira reação observada era de espanto ao ver a cadeira, na qual ele tinha a oportunidade de sentar para jogar o jogo.

\subsubsection{Manete (Controle)}

Desenvolvida com apoio de um controlador digital, $\mathrm{o}$ arduino, a manete capturava a direção para qual o usuário manipulava a cadeira, o objetivo era criar a sensação de que a cadeira no jogo se movia de acordo com o movimento da manete. Para isso ela era conectada ao controlador digital que transforma os comandos analógicos em impulsos digitais, que eram transmitidos até o computador e jogo.

\subsubsection{Captura de Movimento}

O primeiro dispositivo escolhido para o desenvolvimento do projeto foi o Kineckt, dispositivo de captura de movimento desenvolvido pela Microsoft, entretanto, no desenvolvimento $16^{\circ}$ Ergodesign - Congresso Internacional de Ergonomia e Usabilidade de Interfaces Humano Tecnológica: Produto, Informações Ambientes Construídos e Transporte

$16^{\circ}$ USIHC - Congresso Internacional de Ergonomia e Usabilidade de Interfaces Humano Computador

CINAHPA | 2017 - Congresso Internacional de Ambientes Hipermídia para Aprendizagem.

foram encontradas dificuldades que o fizeram ser abandonado. $\mathrm{O}$ jogo foi idealizado para ser jogado em uma área reduzida, pois, tratava-se de um evento, e as especificações do manual do Kineckt exigem no mínimo 1,8 m [XBOX 360], sendo que, a distância ideal para o game projetado era menor que um metro, fazendo com que a captura do Kinect não alcançasse o potencial total. $\mathrm{O}$ segundo ponto foi a sobrecarga gerada no sistema ao utilizar Kinect, que consumia processamento de computador que não tínhamos disponível em nosso instrumento. $\mathrm{O}$ terceiro ponto trata-se do problema encontrado nas saídas USB, que entraram em conflito ao utilizarmos simultâneamente o Kinect, o Arduino e o Óculus Rift.

Para manter o conceito de captura de movimento foi utilizada uma web cam comum e um software chamado Camspace [2009]. Tal software realiza o rastreamento de objetos pela webcam para que sejam utilizados como mouse. Utilizando esse software foi produzido um código que transformava o movimento 2D do mouse na tela em movimento 3D do braço do jogador no jogo. Foi colocado na mão de cada jogador, um objeto amarelo, e ao movimentar-se esse objeto em frente a câmera, tinha-se como consequencia o movimento da mão do jogador no game. Na Figura 3 é possível observar as web cam e o objeto, um tecido amarelo, na mão do jogador.

A web cam captura a imagem, enquanto o software é programado para reconhecer o tecido amarelo como uma âncora de movimento, a partir desse ponto, o mouse passa a seguir o movimento do objeto capturado na tela. Dentro do jogo existe um algoritmo que simula o movimento 3D do braço, baseado na distância do braço do centro da tela.

\subsection{4 Óculos de Realidade Virtual}

Foi utilizado o óculos rift [Oculus], um suporte tecnológico que produz uma sensação de realidade virtual, ao simular um ambiente 3D por meio de suas lentes. Assim, o movimentar da cabeça do usuário é o movimentar da visão do avatar, de modo que é possível que a cabeça do jogador e avatar realizem os mesmos movimentos. Durante a sessão de jogos, um dos pedidos que fazíamos aos 


\section{$16^{\circ}$ \\ ERGODESIGN USIHC CINAHPA}

usuários, era que movimentassem a cabeça para baixo de forma a olhar suas pernas. Utilizando o óculos, eles não viam suas próprias pernas, mas as pernas do personagem $3 \mathrm{D}, \log$, suas pernas como avatar eram de uma pessoa em cadeira de rodas, eles não viam só as pernas, mas também a cadeira de rodas e sua mão se movendo no ambiente virtual. Um dos problemas encontrados no uso do óculos rift é o enjoo relatado por muito dos participantes do experimento, alguns inclusive pediram para deixar o jogo momentos após colocarem o instrumento. Como não era um efeito que se buscava estudar inicialmente, não possuímos dados conclusivos que apontem uma causa.

\section{Respostas}

O sistema escolhido para a coleta de dados foi o Google Forms, uma plataforma gratuita para realizar questionários e apresentar estatísticas. As perguntas foram aplicadas durante a semana de ciêcnia e tecnologia, foi reservada uma sala na escola na qual o projeto foi desenvolvido, onde visitantes da feira poderiam utilizar o game. $\mathrm{O}$ evento ocorreu durante três dias, nos quais foram colhidas 126 entrevistas.

\subsection{Impressão sobre o Jogo}

A primeira pergunta foi em relação ao grau de satisfação do usuário com o jogo, em uma escala de 1 a 5 , na qual 1 é "Muito Ruim" e 5 "Muito Bom". Para evitar uma interferência do entrevistador com o entrevistado, havia um espaço separado para que ele pudesse realizar as respostas, contando com um dos integrantes do projeto, caso necessário, para informar sobre dúvidas relativas as perguntas. $\mathrm{O}$ resultado foi $77 \%$ (97) definiram o jogo como "Muito Bom", 19\% (24) como "Bom" e 4\% (5) "Regular", não ocorreram avaliações do tipo "Muito Ruim"

\subsection{Experiência com Jogos Digitais}

Ao identificar se os usuários já possuíam alguma experiência prévia com jogos digitais, $10 \%$ (13) não responderam a questão, 67\%(85) afirmaram já $16^{\circ}$ Ergodesign - Congresso Internacional de Ergonomia e Usabilidade de Interfaces Humano Tecnológica: Produto, Informações Ambientes Construídos e Transporte

$16^{\circ}$ USIHC - Congresso Internacional de Ergonomia e Usabilidade de Interfaces Humano Computador

CINAHPA | 2017 - Congresso Internacional de Ambientes Hipermídia para Aprendizagem.

possuir experiência com jogos digitais e $22 \%$ (28) afirmaram não possuir experiência anterior.

\subsection{Imersão com o Jogo}

Uma das perguntas buscava compreender o quão imerso no jogo os usuários se sentiram dentro de uma escala de 1 a 5, na qual 1 representa "Pouco Imersivo" e 5 "Muito Imersivo". Analisando os dados a imersão do jogo foi alta, 56,3\% (71) o consideraram "Muito Imersivo" como avaliação 5, $31 \%$ (39) atribuíram nota 4, 7,9\%(10) deram nota 3, entendendo uma Imersão "Mediana", 3,2\%(4) o consideraram abaixo da média e 1,6\%(2) pessoas o entenderam como "Pouco Imersivo".

\subsection{Dificuldade para utilizar os controles}

O alto grau de imersão pode encontrar resposta no fato de quase $50 \%$ dos jogadores terem apontado os controles como "Muito Fácil" 34,1\%(43) e "Fácil" 15,1\%(19). Apontaram uma dificuldade "Média" 23,8\%(30) dos usuários. As pessoas que encontraram dificuldades se dividiram entre "Difícil" 17,5\%(22) e "Muito Difícil" 9,5\%(12). Portanto, entende-se que a maior parte dos participantes não encontrou dificuldade substancial para utilizar os controles de jogo.

Devemos lembrar que os controles buscavam replicar o uso cotidiano de uma pessoa em cadeira de rodas, portanto, um dos controles era uma manete plugada a cadeira, que simulava o controle de uma cadeira de rodas motorizada e o outro controle era a captura da posição da mão do jogador. Nesse sentido, não existem botões que transmitam um comando para outro, cada ação no mundo virtual é guiada por uma ação similar no mundo não virtual.

\subsection{Uso de cadeira de rodas para realizar atividades}

Quando questionados se realizariam as atividades mais rápido sem o uso de cadeira de rodas, $71,2 \%$ (89) das pessoas acredita que poderiam realizar as atividades de maneira mais célere, enquanto $26,4 \%$ (33) acredita que não faria diferença e $2,4 \%$ (3) não soube opinar.
Realização:

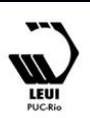




\section{$16^{\circ}$ \\ ERGODESIGN USIHC CINAHPA}

\subsection{Percepção das dificuldades encontradas por pessoas em cadeiras de rodas}

$95,2 \%$ (120) das pessoas afirmaram que o jogo contribui para perceber as dificuldades que as pessoas em cadeiras de rodas encontram em seu cotidiano, e 4,8\%(6) do participantes relataram que o jogo não contribui no processo.

Das pessoas que responderam, 93,7\%(118) concordam que o jogo desenvolvido pode sensibilizar as pessoas para a vivência e obstáculos das pessoas em cadeiras de rodas, $4,8 \%$ não concordam e $1,6 \%$ (2) não souberam opinar.

\section{Análise}

Foi possível perceber que o jogo é uma importante forma de provocar empatia pois, "o sujeito representa seu papel no jogo de acordo com o que julga o mais adequado para isso, contrariando, em determinados momentos ou situações, suas atitudes e postura assumidas na vida real." (SATO, p.41).

Sendo assim, foi necessário criar uma ambientação que estreitasse a relação do jogador com o personagem que ele representa. Em nosso jogo: Jogador - Pessoa sem deficiência física / Personagem - Avatar em cadeira de rodas

Figura 4

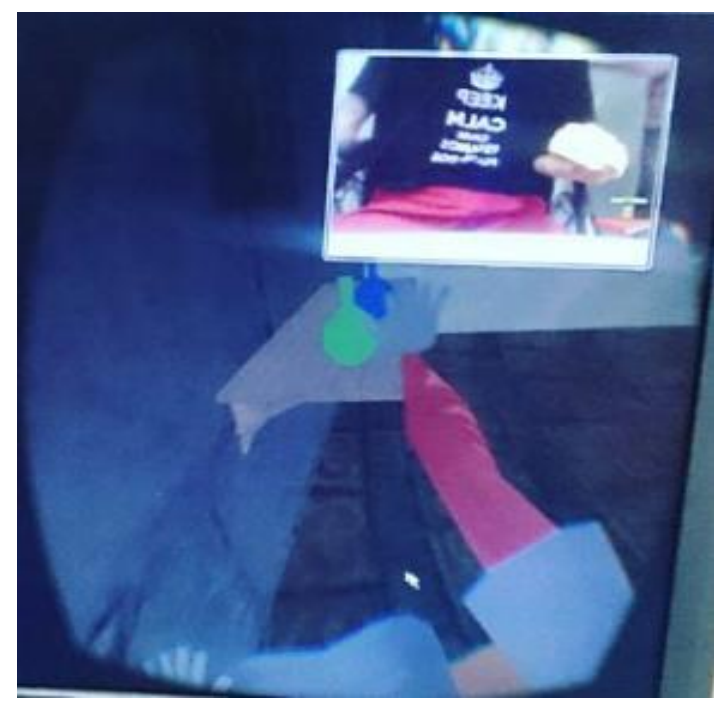

Figura 4 Jogador e Avatar realizando mesma ação, o jogador se movimenta no mundo virtual por meio do $16^{\circ}$ Ergodesign - Congresso Internacional de Ergonomia e Usabilidade de Interfaces Humano Tecnológica: Produto, Informações Ambientes Construídos e Transporte

$16^{\circ}$ USIHC - Congresso Internacional de Ergonomia e Usabilidade de Interfaces Humano Computador

CINAHPA | 2017 - Congresso Internacional de Ambientes Hipermídia para Aprendizagem. avatar que está em uma cadeira de rodas.

Fonte: Própria

Boal, se referindo ao teatro, analisa que "quando o espetáculo começa se estabelece uma relação entre o personagem (especialmente o protagonista) e o espectador" [2013, p.57], o autor define empatia como "uma relação emocional entre personagem e espectador" [2013, p.57] ela, empatia, "consiste em justapor duas pessoas (uma fictícia, outra real)" [2013, p.57].

"A empatia funciona mesmo que exista uma colisão de interesses entre o universo fictício e o universo real dos espectadores" [Boal, 2013, p.120]. Quando pensamos em jogos eletrônicos podemos entender que "o prazer e a diversão estão em representar (jogar verdadeiramente) no jogo, não exatamente no que representar". [Sato, 2009, p.41].

Entendemos a representação no teatro e videogame como possuindo semelhanças, porque "o público adota as regras do jogo, como ao jogar qualquer jogo." [BOAL, 2013, p.120]. Courtney [2010] ao teorizar sobre o teatro difere dois tipos de jogos, jogo dramático e jogo de regras. O jogo dramático que contém personificação, esse jogo se encaixa no teatro ao qual Boal se refere. O jogo de regras que é a formalização do jogo (brincadeira) em modelos com regras.

Ainda, "têm-se demonstrado que os assim chamados jogos puros com regras são, essencialmente, jogos com situações imaginárias"[VIGOTSKI, 2007, p.112], o que nos leva a afirmar que o jogo digital é a fusão de representação (situações imaginárias) com as regras, uma vez que o jogador só consegue experienciar o mundo digital por meio do avatar, e para realizar essa experiência ele deve se submeter às regras daquele mundo.

Analisamos o jogo como uma visão integradora, onde os sistemas de narrativas existentes nos jogos se mesclam de maneira profunda ao sistema de regras, percepção compartilhada por GASI [2014]: "videogames são compostos de narrativas ludológicas" [2014, p.44]. 


\section{$16^{\circ}$ \\ ERGODESIGN USIHC CINAHPA}

$16^{\circ}$ Ergodesign - Congresso Internacional de Ergonomia e Usabilidade de Interfaces Humano Tecnológica: Produto, Informações Ambientes Construídos e Transporte

$16^{\circ}$ USIHC - Congresso Internacional de Ergonomia e Usabilidade de Interfaces Humano Computador

CINAHPA | 2017 - Congresso Internacional de Ambientes Hipermídia para Aprendizagem.
É importante ressaltar que concordamos com as analises apresentadas no estudo de SILVA et al [2015] sobre a teoria das emoções e como ela pode ser aplicada para produzir um ambiente estimulante para o "usuário (jogador/aprendiz)" SILVA et al [2015, p.12], entretanto em nosso estudo não nos referimos ao uso de gamificação, mas sim de jogo digital.

\section{Conclusão}

Acreditamos que os jogos são capazes de causar empatia em seus usuários. No caso do game apresentado nesse artigo, conclui-mos que ele é capaz de provocar empatia do jogador para com as pessoas em cadeiras de rodas, por meio da experiência de representar uma pessoa em cadeira de rodas em um jogo virtual. Essa percepção se baseia no alto índice de aprovação das pessoas que utilizaram o game e sentiram-se frutradas com as dificuldades de realizar atos simples e "tocadas" pelos desafios vivenciados por pessoas que necessitam utilizar cadeira de rodas diariamente.

Logo, a experiência que realizamos, aponta, em nossa percepção, que os jogos digitais têm a capacidade de permitir que seus usuários vivenciem outras realidades e experimentem as dificuldades e desafios alheios a seu cotidiano, seguida da reflexão dos mesmos sobre a situação vivida. Entretanto não nos colocamos como utopistas, que acreditam que o simples ato do jogar irá mudar a sociedade, mas defendemos que produtos culturais, como os jogos digitais, possuem o poder de gerar empatia e contribuir com relações mais harmônicas na sociedade.

Nesse sentido, os jogos digitais, se mostram uma ferramenta de grande utilidade para discutir temas sensíveis e delicados da sociedade, tendo a capacidade de provocar reflexão social.

\section{BIBLIOGRAFIA}

ALECRIM, 2014. A Invisibilidade Dos Alunos Com Deficiência Na Escola. Disponível em: <Http://www.Ebah.Com.Br/Content/Abaaagiiwai/ A-Invisibilidade-Dos-Alunos-Com-Deficiencia-

\section{Na-Escola >}

BRASIL, Lei Brasileira De Inclusão Da Pessoa Com Deficiência. Disponível em: < http://www.Planalto.Gov.Br/Ccivil_03/_Ato20152018/2015/Lei/L13146.Htm >

BOAL, A. 2013. Teatro do Oprimido e as outras poética políticas. São Paulo: Cosacnaify, 2013.

CAMSPACE, Software, 2009 Disponível em: <http://www.camspace.com>

CEDRO, C. C. Betini, R. C. 2014. Avaliação Da Acessibilidade Em Tecnologias Assistivas Baseadas Em Realidade Aumentada Através De Um Modelo Preditivo - Usar Xxiv Congresso Brasileiro De Engenharia Biomédica - Cbeb 2014

COURTNEY, R. Jogo, teatro \& pensamento : as bases intelectuais do teatro na educação. São Paulo: 4 Ed, Perspectiva, 2010.

CRUZ JUNIOR, G. DA SILVA, E.M. A (Ciber)Cultura Corporal No Contexto Da Rede: Uma Leitura Sobre Os Jogos Eletrônicos Do Século Xxi. Revista Brasileira De Ciências Do Esporte, Florianópolis, SC, V. 32, N. 2-4, Jan. 2011. ISSN 2179-3255. Disponível Em: <Http://Revista.Cbce.Org.Br/Index.Php/RBCE/Art icle/View/637>. Acesso Em: 23 Set. 2015.

GASI, F. Videogames e mitologia: a poética do imaginário e dos mitos gregos nos jogos eletrônicos. Nova Iguaçu, RJ: Marsupial Editora, 2013

GONÇALVES, F. C. Atitudes Dos Alunos Sem Deficiência Face À Inclusão Nas Aulas De

Educação Física: Estudo Exploratório Dos Alunos Do $3^{\circ}$ CEB Face À Inclusão Nas Aulas De Educação Física. Disponível em: < http://Hdl.Handle.Net/10316/12033 > 13/03/2016

GOMES, R. Shenmue E O Dilema Narrativo. In: Orgs. SANTAELLA, Lucia. FEITOZA, Mirna. Mapa Do Jogo. São Paulo: Cengage Lerning.2009.P67-84.

MACHADO, A Apud SATO, A. K. O. Do Mundo
Realização:

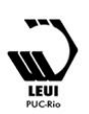




\section{$16^{\circ}$ \\ ERGODESIGN USIHC CINAHPA}

$16^{\circ}$ Ergodesign - Congresso Internacional de Ergonomia e Usabilidade de Interfaces Humano Tecnológica: Produto, Informações Ambientes Construídos e Transporte

$16^{\circ}$ USIHC - Congresso Internacional de Ergonomia e Usabilidade de Interfaces Humano Computador

CINAHPA | 2017 - Congresso Internacional de Ambientes Hipermídia para Aprendizagem.

Real Ao Ficcional: A Imersão No Jogo In: Orgs. SANTAELLA, L. FEITOZA, M. Mapa Do Jogo. São Paulo: Cengage Lerning.2009.P37-48.

OCULUS. Óculos de Realiadade Virtual.

Disponível em: <https://www.oculus.com>

RAMALHO, M. M. FAUSTINO, Paulo R C. MOREIRA, G. B S M. SILVA, L. D. MACHADO, A. F V. CLUA, E. 2014 Audiogame Fuga: Desenvolvimento E Avaliação De Um Jogo Assistivo Com Kinect Para Deficiente Visuais SBC - Proceedings Of Sbgames 2014 | ISSN: 21792259

SANTAELla, L. Culturas E Artes Do PósHumano: Da Cultura Das Mídias À Cibercultura. São Paulo : 1.Ed 5.Reimp. Paulus, 2003

SENS, A. L. PEREIRA, A.T. C. (2015) Reflexões Sobre $O$ Design De Jogos Digitais Acessíveis: Casos Papa Sangre E Blindside. Disponível em: $<$ http://Conahpa.Sites.Ufsc.Br/WpContent/Uploads/2015/06/ID37_Sens-Pereira.Pdf >

SILVA. F. C. P. ULBRICTH. R. V. ADAMS.

DOMINIQUE. SCUDELARI. C. Gamificação na Educação: A importância da teoria das emoções como estratégia na análise de jogos educacionais. Disponível em: $<$ http://conahpa.sites.ufsc.br/wpcontent/uploads/2015/06/ID73_Poletto-UlbrichtAdams-Scudelari.pdf>

VIGOTSK, L. S. (2007) A Formação Social Da Mente. São Paulo: 7.Ed Martins Fontes, 2007

XBOX 360. Guia de Início Rápido do Kinect. Disponível em: <https://support.xbox.com/ptBR/xbox-360/console/manual-specs >

\section{Agradecimentos}

Agradecemos as instituições CEET Vasco Coutinho e Secti por colaborar na realização do projeto, fomentando e cedendo o espaço durante a semana de ciência e tecnologia. 